\title{
Distribution of Side Abutment Stress in Roadway Subjected to Dynamic Pressure and Its Engineering Application
}

\author{
Yao Qiangling, ${ }^{1,2}$ Zhou Jian,, $^{1,2}$ Li Yanan, ${ }^{1,2}$ Tan Yingming, ${ }^{1,2}$ and Jiang Zhigang ${ }^{1,2}$ \\ ${ }^{1}$ School of Mines, China University of Mining and Technology, Xuzhou 221008, China \\ ${ }^{2}$ Key Laboratory of Deep Coal Resource Mining, CUMT, Ministry of Education, Xuzhou 221008, China \\ Correspondence should be addressed to Zhou Jian; zhou136090@126.com
}

Received 12 September 2014; Accepted 20 December 2014

Academic Editor: Shimin Liu

Copyright (c) 2015 Yao Qiangling et al. This is an open access article distributed under the Creative Commons Attribution License, which permits unrestricted use, distribution, and reproduction in any medium, provided the original work is properly cited.

\begin{abstract}
The borehole stress-meter was employed in this study to investigate the distribution of the side abutment stress in roadway subjected to dynamic pressure. The results demonstrate that the side abutment stress of the mining roadway reaches a peak value when the distance to the gob is $8 \mathrm{~m}$ and the distribution curve of the side abutment stress can be divided into three zones: stress rising zone, stress stabilizing zone, and stress decreasing zone. Further numerical investigation was carried out to study the effect of the coal mass strength, coal seam depth, immediate roof strength, and thickness on the distribution of the side abutment stress. Based on the research results, we determined the reasonable position of the mining roadway and the optimal width of the barrier pillar. The engineering application demonstrates that the retention of the barrier pillar with a width of $5 \mathrm{~m}$ along the gob as the haulage roadway for the next panel is feasible, which delivers favorable technological and economic benefits.
\end{abstract}

\section{Introduction}

As the coal in a longwall panel is being extracted, the surrounding strata are forced to move toward and fill the voids left by the extracted coal [1]. This process induces a series of intensive activities which include movements of the overlying strata, abutment stress on both sides of the panel, abutment stress in front and rear of the panel, and the severe deformation of the adjacent roadways. A key issue in longwall mining is to understand the distribution characteristics of the abutment stress, including side abutment stress, font and rear abutment stress, providing some basis for the layout of the adjacent roadways.

Researches on the distribution characteristics of the abutment stress at a longwall mining face were done by a lot of scholars, achieving fruitful and useful results [2-7]. Zhang et al. (2011) studied the effects of coal hardness, coal seam thickness, and advancing speed of the panel on the position of the maximum abutment stress and obtained the empirical formulas used for determining the peak position [8]. Xu et al. (2012) studied the front abutment stress of a fully mechanized coalface of 11061 soft coal isolated islands of Liangbei Coal Mine using a self-developed mining-induced stress monitoring system associated with electromagnetic radiation technology and discussed the effects of abutment stress distribution on strata behavior [9]. Qin and Wang analyzed and studied the distribution of abutment stress and its transmission law in floor at the fully mechanized caving face of isolated island in 4303 deep shaft of Dongtan Coal Mine [10]. Zhang et al. studied the distribution of lateral floor abutment stress at a working face. Firstly, they used elasticity theory to establish a distribution model of lateral floor abutment stress and then analyzed its distribution characteristics. Secondly, they established a three-dimensional numerical simulation model by using FLAC3D (ITASCA Consulting Group) software [11]. Whittaker and Potts (1974) developed an empirical approach to calculate the vertical stress ahead of the longwall face for rock conditions prevailing in the UK. In his approach, a yield zone exists ahead of the face. The vertical stress is zero both at the face and at the rib side. It increases quickly with the distance from the face [12].

Therefore, it is very important to make clear the distribution characteristics and scope of influence of the abutment stress, because it can provide the references for adopting reasonable supporting patterns, determining the position 


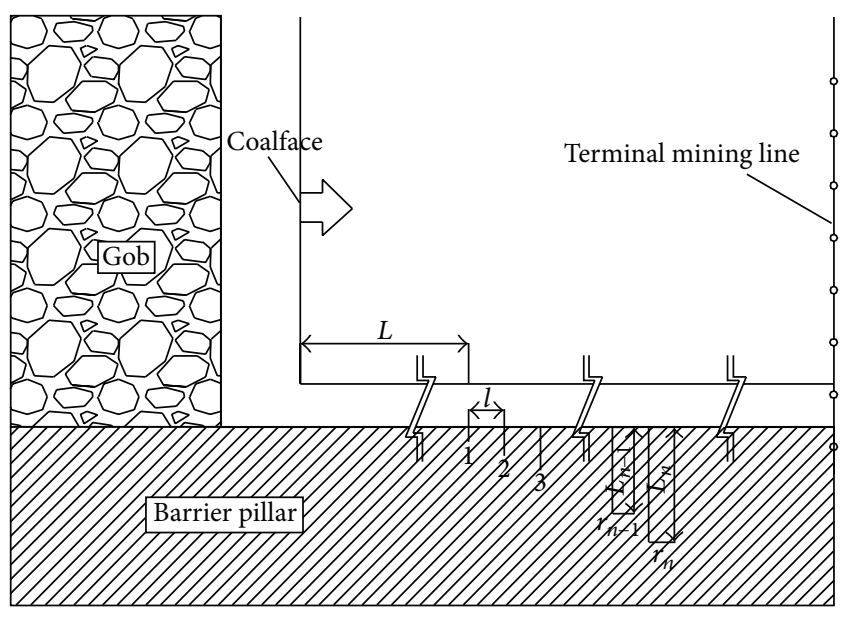

FIGURE 1: Layout of the side abutment stress observation station. $L$ represents the distance of the first borehole stress-meter to the coalface, which should be larger than the scope of influence of the front abutment stress; $r_{n}$ represents the number of the observation station; $L_{n}$ represents the length of the borehole stress-meter, which is in general $1 \sim 2 \mathrm{~m} ; l$ represents the space between the boreholes, which is in general $2 \sim 3 \mathrm{~m}$.

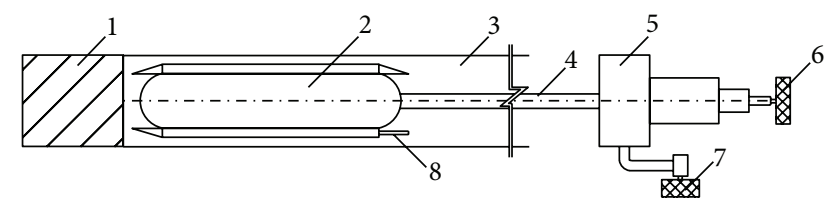

(1) Coal mass

(2) Borehole stress-meter

(5) Pressure and frequency converter

(3) Borehole

(4) Pressure pipe

(6) Pressure recorder

(7) Manual hydraulic pump

(8) Plug

FIGURE 2: Installation drawing for the borehole stress-meter.

of the adjacent roadway, preventing the dynamic disasters induced by mining, and so forth. Some instruments and methods are adopted to investigate the distribution of the abutment stress [13,14], of which borehole stress-meter is the most commonly used [15]. Thus, in this study, we firstly use the borehole stress-meter to monitor the distribution characteristics of the side abutment stress during the extraction of the longwall panel in Qianyingzi mine, China. Then we use the UDEC numerical simulation software to investigate the factors affecting the distribution of the side abutment stress. Based on the field monitoring and simulation results, we determined the reasonable layout position of the mining roadway and the optimal width of the barrier pillar between panels. Finally, a field application was carried out. The final engineering application further validates the reliability of the field monitoring and numerical simulation results. Therefore, this study could provide some beneficial references to the designing of the barrier coal pillar in roadway subjected to dynamic pressure.

\section{Field Monitoring Principles and the Observation Instrument}

2.1. Field Monitoring Principles for Side Abutment Stress. The borehole stress-meter is used to monitor the distribution of the abutment stress in roadway subjected to dynamic pressure. Firstly, we lay out the stress observation borehole in areas free from the impact of the moveable front abutment stress. The parameters of the boreholes mainly include space between the boreholes and depth of the borehole. Secondly, we install the stress-meters on these boreholes to monitor the stress changes with the advance of the coalface. The pressure recorder connected to the borehole stress-meter can record all the changes of the stress values, from which we can obtain the curve representing the relation between the side abutment stress and the distance to the gob. The layout of the side abutment stress observation station is illustrated in Figure 1. The specific number and depth of the boreholes are adjusted in line with the in situ geological settings.

As shown in Figure 1, $r_{n}$ borehole stress-meter observation stations are laid out within the barrier pillar between panels. The specific numbers of the stations are closely related to the actual engineering requirements and the required precision of the acquired data. The boreholes in each observation station are installed with a stress-meter. The diameter of each borehole is $48 \mathrm{~mm}$ and the space between boreholes is $2 \mathrm{~m}$. The borehole is perpendicular to the roadway rib with $1.5 \mathrm{~m}$ distance to the roadway floor.

2.2. Observation Instrument. The instruments used for monitoring the distribution of the side abutment stress mainly include the borehole stress-meter with a model number of KSE-II-1, the string wire pressure recorder with a model number of KSE-III, the steel wire data acquisition system with a model number of KSE-III, and the manual hydraulic pump. All of these instruments are made by Shandong Haozhou Mining Safety Equipment Corporation, China. The installation drawing for the borehole stress-meter is illustrated in Figure 2.

The installation steps for the observation instruments are as follows: (1) use the special drill rod to insert the plug (as shown in Figure 2) and slowly push the borehole stress-meter into the borehole; (2) connect the pressure pipe, the pressure and frequency converter, and manual hydraulic pump to the borehole stress-meter, respectively; (3) inject the oil into the borehole stress-meter through the manual hydraulic pump; during the injection, the pump pressure should be slowly increased until the borehole stress-meter fills the borehole; (4) the pump pressure should be continuously increased to make sure that the reading of the pressure gauge of the manual hydraulic pump stabilizes at a preset initial pressure value and maintains the value for 5 10 $\mathrm{min}$; (5) release the pump pressure and observe the changes of the pressure gauge reading; if the reading cannot stabilize at the preset initial pressure value (for measuring the rising value of the abutment stress, the initial pressure is $4.0 \sim 5.0 \mathrm{MPa}$ ), then steps 3 and 4 should be repeated until the initial pressure reaches stable; (6) install and activate the pressure recorder to record the borehole stress values; the pressure recorder can record the 


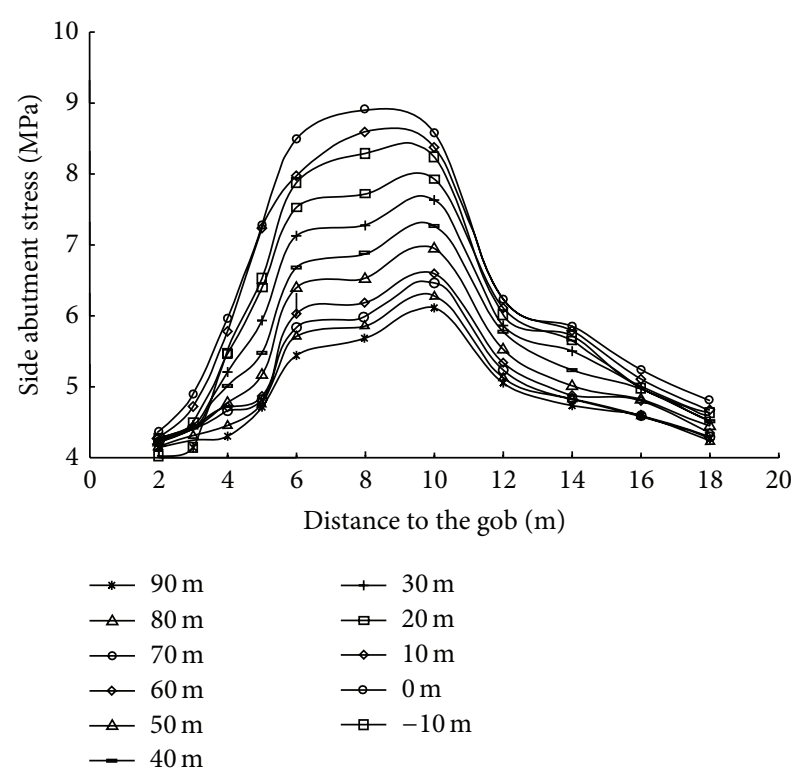

FIgURE 3: Measured curve of the distribution of the side abutment stress in Qianyingzi mine. In the figure: $-10 \mathrm{~m}, 0 \mathrm{~m}, 10 \mathrm{~m}, \ldots, 90 \mathrm{~m}$ represents the horizontal distance of the borehole stress-meter to the gob, respectively; the initial pressure of the borehole stress-meter is 4.0 MPa.

data automatically and the recording interval can be adjusted according to actual requirements. After the installation, the user should use the steel wire data acquisition system to gather the recorded data every day or every other day and import the acquired data to the computer for data processing.

\section{Field Monitoring of the Side Abutment Stress}

The borehole stress-meter was adopted to investigate the distribution of the side abutment stress in the $3_{2} 12$ coalface of Qianyingzi coal mine, China, where mining activity is carried out in the $3_{2}$ coal seam. The characteristics of the coal seam are shown in Table 1 .

In processing the acquired data, we plot the abutment stress obtained from the points with the same distance to the coalface in the seam plane in order to clearly present the distribution characteristics of the side abutment stress. Figure 3 shows the "side abutment stress versus distance to the gob" curve with the advance of the $3_{2} 12$ coalface. Due to the restrictions imposed by the coal seam strength and its intactness, the borehole stress-meter cannot reach the area where the stress is in a primitive state. Thus the pressure values presented in Figure 3 are relative values representing the rising side abutment stress. The significance of this curve lies in that it can help us to gain a better understanding of the distribution characteristics of the side abutment stress and to obtain some key parameters related to the side abutment stress, such as the stress rising zones at the coal wall side and the peak value of the side abutment stress, providing a basis for the retention of the barrier coal pillar between panels.

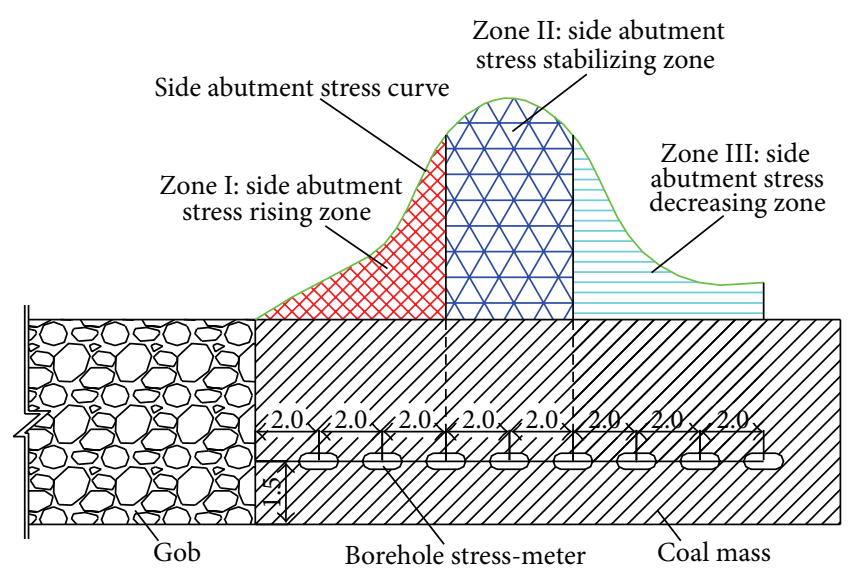

FIGURE 4: Zone chart of the distribution of the side abutment stress.

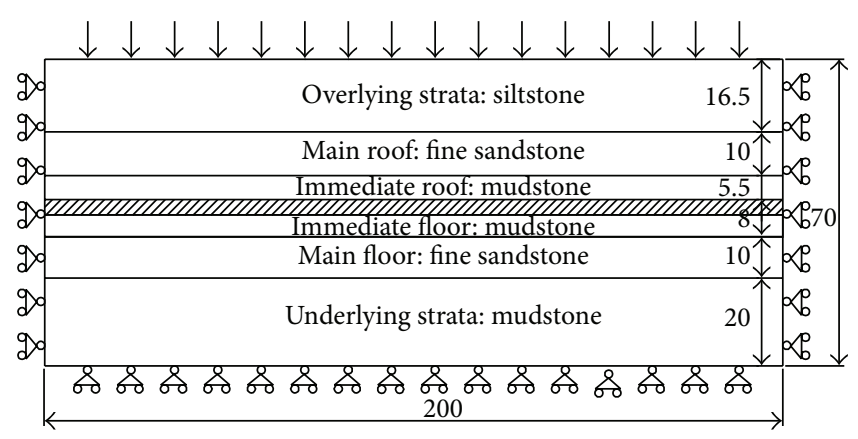

Figure 5: Numerical simulation model.

Figures 3 and 4 show the following. (1) With the advance of the coalface (the advancing direction can be referred to in Figure 1), the side abutment stress gradually increases; (2) Zone I, also termed pillar plastic zone, is $2 \sim 6 \mathrm{~m}$ in width, where the side abutment stress is on the rise; (3) Zone II, also called limit elastic zone, is $6 \sim 10 \mathrm{~m}$ in width, where the side abutment stress reaches stable; the side abutment stress reaches a peak value of $9.0 \mathrm{Mpa}$ when the distance to the gob is $8 \mathrm{~m}$; this should be taken into adequate consideration while laying out the roadway; (4) Zone III is in general $10 \mathrm{~m}$ away from the gob, where the side abutment stress is smaller than the peak value and gradually decreases until reaching the primitive stress; this zone is called side abutment stress decreasing zone.

\section{Numerical Investigation into the Factors Affecting the Side Abutment Stress}

Selecting the geological setting in Qianyingzi mine as the study site, we adopt the UDEC numerical simulation software to investigate the factors influencing the distribution characteristics of the side abutment stress. The numerical simulation model is illustrated in Figure 5. The physical and mechanical properties of various strata were initially acquired from drilling log and exploration results. Then, the borehole camera was employed to examine the integrity of the rock mass. The final simulation parameters in this study were 
TABLE 1: Characteristics of the $3_{2}$ coal seam.

\begin{tabular}{|c|c|c|c|c|c|}
\hline Coal mine & Coal seam & Geologic age & Average depth/m & Average thickness/m & Roof and floor strata \\
\hline Qianyingzi & $3_{2}$ seam & $\begin{array}{l}\text { Permo-carboniferous } \\
\text { period } \\
\text { Lower Shihezi formation }\end{array}$ & 600 & 3.3 & $\begin{array}{l}\text { Immediate roof: } \\
\text { 4.3-meter-thick mudstone; } \\
\text { Main roof: } 11.5 \text {-meter-thick } \\
\text { fine sandstone; } \\
\text { Immediate floor: } \\
\text { 2.9-meter-thick mudstone; } \\
\text { Main floor: } 9.5 \text {-meter-thick } \\
\text { fine sandstone }\end{array}$ \\
\hline
\end{tabular}

TABLE 2: Physical and mechanical properties of various strata.

\begin{tabular}{|c|c|c|c|c|c|c|c|c|}
\hline Stratum name & Rock type & Thickness/m & $\begin{array}{c}\text { Bulk } \\
\text { modulus/GPa }\end{array}$ & $\begin{array}{c}\text { Shear } \\
\text { modulus/GPa }\end{array}$ & Density $/ \mathrm{kg} \cdot \mathrm{m}^{-3}$ & $\begin{array}{c}\text { Friction } \\
\text { angle } /^{\circ}\end{array}$ & Cohesion/MPa & $\begin{array}{c}\text { Tensile } \\
\text { strength/MPa }\end{array}$ \\
\hline $\begin{array}{l}\text { Overlying } \\
\text { strata }\end{array}$ & Siltstone & 16.5 & 8.4 & 4.8 & 2450 & 32 & 5.6 & 3.6 \\
\hline Main roof & $\begin{array}{c}\text { Fine } \\
\text { sandstone }\end{array}$ & 10 & 10 & 5.8 & 2580 & 38 & 7.8 & 4.5 \\
\hline $\begin{array}{l}\text { Immediate } \\
\text { roof }\end{array}$ & Mudstone & 5.5 & 3.2 & 2.5 & 2460 & 32 & 2.6 & 2.8 \\
\hline Coal seam & Coal & 3.5 & 2.3 & 1.2 & 1340 & 24 & 1.6 & 2 \\
\hline $\begin{array}{l}\text { Immediate } \\
\text { floor }\end{array}$ & Mudstone & 4.5 & 2.8 & 1.5 & 2480 & 28 & 3.5 & 4.2 \\
\hline Main floor & $\begin{array}{c}\text { Fine } \\
\text { sandstone }\end{array}$ & 10 & 5.2 & 2.3 & 2520 & 28 & 9.6 & 3.8 \\
\hline $\begin{array}{l}\text { Underlying } \\
\text { strata }\end{array}$ & Mudstone & 20 & 4.7 & 2.7 & 2500 & 30 & 7.5 & 1.6 \\
\hline
\end{tabular}

determined from the experience of Shen (2014) and Gao et al. (2014), which are given in Table $2[16,17]$.

Considering the speed of the numerical calculation, we reasonably simplify the model size in order to slash the calculation time. Based on the engineering experience, we select a reasonable influencing depth and width and determine the model size as $200 \times 70 \mathrm{~m}$, as shown in Figure 5 . As we mentioned before, the coal seam has a depth of $600 \mathrm{~m}$. Thus an equivalent vertical stress of $15.0 \mathrm{MPa}$ is applied to the upper boundary of the model. The left, right, and bottom boundary are all fixed. So they have no vertical velocity and vertical displacement. The constitutive relation used in this model is Mohr-Coulomb model. During the simulation, the panel is stepwise excavated, with the excavation step being $4 \mathrm{~m}$, which could effectively simulate the progressive caving of the overlying strata. We establish this model in an attempt to investigate the distribution characteristics of the side abutment stress with the advance of the former panel and compare the abutment stress before mining and after mining, thus providing some basis for the designing of the roadway subjected to dynamic pressure.

Previous studies demonstrate that $[15,18,19]$ factors that heavily influence the distribution characteristics of the side abutment stress mainly include coal mass strength, coal seam depth, immediate roof strength and thickness, and breakage position of the main roof. In addition, key parameters that are commonly used to represent the distribution characteristics of the side abutment stress generally include the position and magnitude of the peak stress and the stress concentration coefficient and the scope of influence of the stress.

4.1. Influences of the Coal Mass Strength. In terms of its strength, the coal mass can be divided into three categories: soft coal, medium hard coal, and hard coal [20]. This classification has gained wide recognition and practicality in China. The mechanical parameters for the coal of different category are shown in Table 3 . These parameters are in line with Mohr-Coulomb criterion, which are used by most of the scholars and can still reflect the essence of the research problem. The parameters for other strata are given in Table 2. The distributions of the side abutment stress for soft coal, medium hard coal, and hard coal are illustrated in Figure 6.

Figure 6 shows that (1) the strength of the coal mass exerts a significant influence on the position of the peak value of the side abutment stress, while having no pronounced impact on its peak value and the influence of scope; (2) for the hard coal, the stress reaches a peak value when the distance to the gob is $7.2 \mathrm{~m}$, while it is $9.2 \mathrm{~m}$ and $16.5 \mathrm{~m}$ for the medium hard coal and soft coal, increasing $27.8 \%$ and $129.2 \%$, respectively; (3) the lower the coal mass strength, the larger the stress decreasing zone in the solid coal mass; the stress decreasing zone is caused by the side abutment stress during the advance of the former panel; (4) the width of the stress decreasing zone for soft coal is 6 times larger than that for hard coal, indicating the significant influences of the coal mass strength on the layout of the mining roadway. 


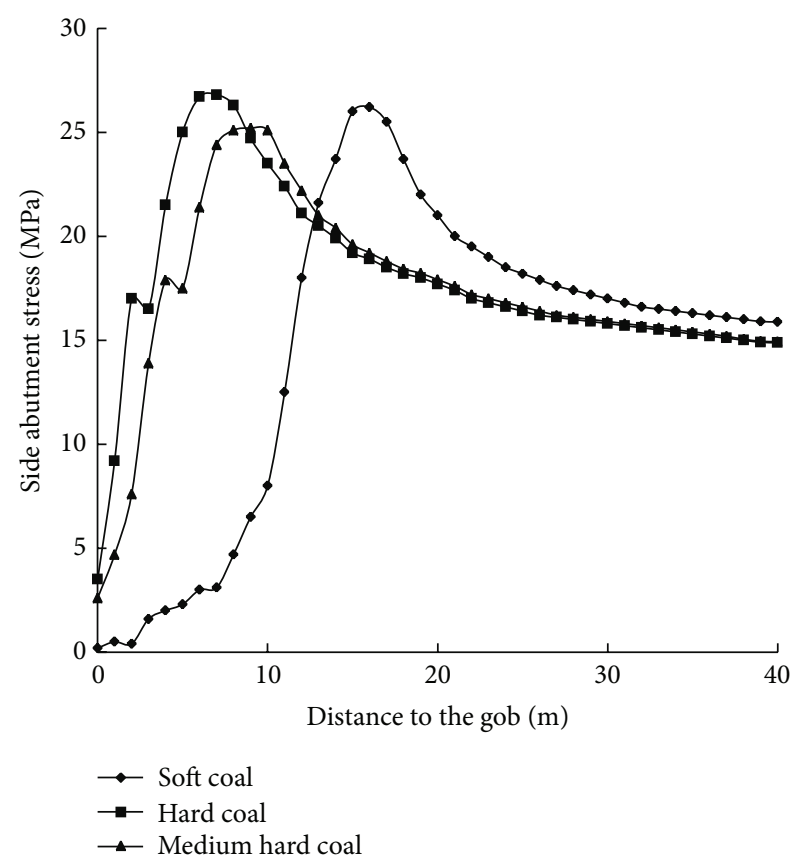

FIGURE 6: Distribution of the side abutment stress for coal of different category.

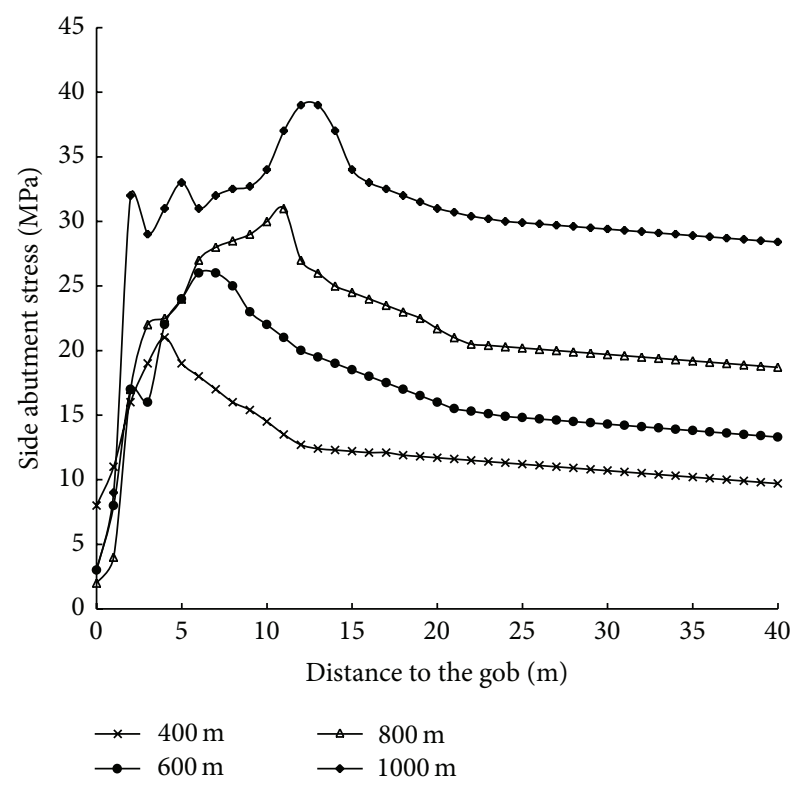

FIGURE 7: Distribution of the side abutment stress for coal seams with different depth.

4.2. Influences of the Coal Seam Depth. The average depth of the coal mines in China is about $600 \mathrm{~m}$, with the deepest reaching $1400 \mathrm{~m}$. In addition, coal mines in China are advancing to the deep area with a speed of $8 \sim 12 \mathrm{~m}$ per year $[21,22]$. We select the representative depth of the coal seam in this study as $400 \mathrm{~m}, 600 \mathrm{~m}$, and $1000 \mathrm{~m}$, respectively. The distribution of the side abutment stress for coal seams with different depth is shown in Figure 7.

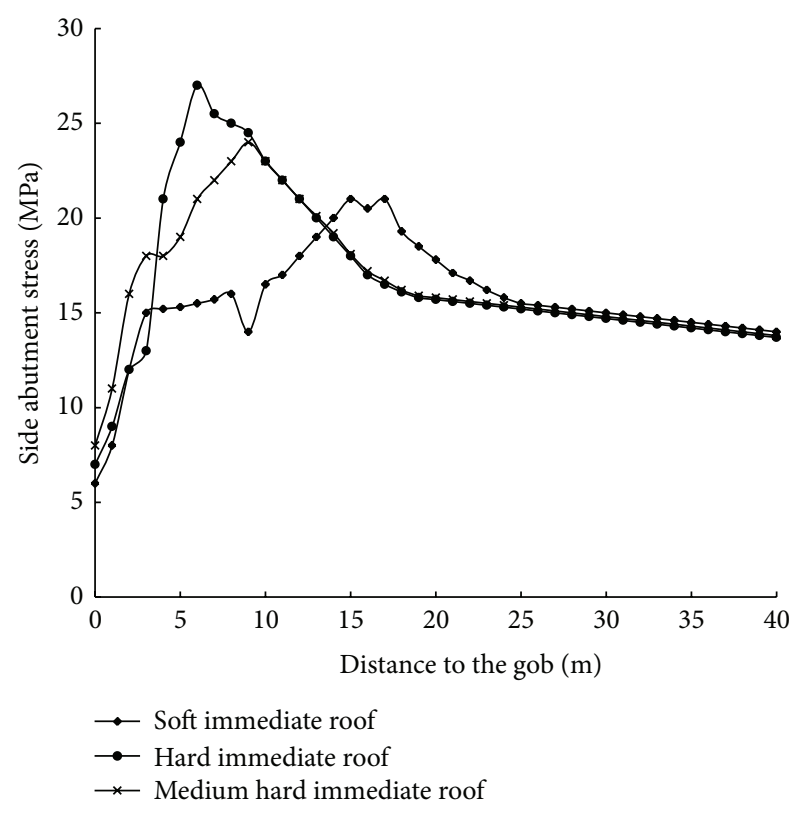

FIGURE 8: Distribution of the side abutment stress for the immediate roof with different strength.

Figure 7 shows that (1) with the increase of the depth, both the position and value of the peak stress have changed; (2) when the depth of the coal seam is $400 \mathrm{~m}, 600 \mathrm{~m}, 800 \mathrm{~m}$, and $1000 \mathrm{~m}$, the concentration coefficient of the corresponding side abutment stress is $2.2,1.78,1.62$, and 1.59 , respectively, demonstrating a decreasing trend; the position of the corresponding peak stress is $5.0 \mathrm{~m}, 7.5 \mathrm{~m}, 10 \mathrm{~m}$, and $10 \mathrm{~m}$ to the gob, respectively.

\subsection{Influences of the Immediate Roof Strength and Thickness}

4.3.1. The Strength of the Immediate Roof. The physical and mechanical properties of other strata remain unchanged, which can be referred to in Table 2 . Table 4 shows the physical and mechanical properties of the immediate roof. Selection of these parameters is in line with the Mohr-Coulomb criteria. Then we run the numerical simulation to investigate the influences of the changes of the immediate roof strength on the distribution characteristics of the side abutment stress. The distribution of the side abutment stress for the immediate roof with different strength is illustrated in Figure 8.

Figure 8 shows that (1) with the change from the hard immediate roof to soft immediate roof, the value of the peak side abutment stress gradually diminishes with the position of the peak stress getting away from the gob; (2) when the immediate roof is soft rock, medium hard rock, and hard rock, the distance of the position of the peak stress to the coal wall at the gob is $12.3 \mathrm{~m}, 9.2 \mathrm{~m}$, and $5.2 \mathrm{~m}$, respectively, demonstrating a decreasing trend; compared to the hard immediate roof, this distance for the soft immediate roof and medium hard immediate roof increases to $136.5 \%$ and $76.9 \%$, respectively; (3) when the immediate roof is soft rock, medium hard rock, and hard rock, the concentration coefficient of the corresponding side abutment stress is 1.51, 
TABLE 3: Mechanical parameters for the coal of different category.

\begin{tabular}{lccccc}
\hline Category & Bulk modulus/GPa & Shear modulus/GPa & Friction angle/ & Cohesion/MPa & Tensile strength/MPa \\
\hline Soft coal & 1.4 & 0.8 & 22 & 1.2 & 1.6 \\
Medium hard coal & 2.3 & 1.2 & 24 & 1.6 & 2 \\
Hard coal & 4.8 & 2.5 & 32 & 4.6 & 3.2 \\
\hline
\end{tabular}

TABLE 4: Physical and mechanical properties of the immediate roof with different strength.

\begin{tabular}{lccccc}
\hline Category & Bulk modulus/GPa & Shear modulus/GPa & Friction angle $\left(^{\circ}\right)$ & Cohesion/MPa & Tensile strength/MPa \\
\hline Soft immediate roof & 1.8 & 1.2 & 28 & 1.8 & 1.2 \\
Medium hard immediate roof & 3.2 & 2.5 & 32 & 2.6 & 2.8 \\
Hard immediate roof & 6.4 & 3.6 & 35 & 3.6 & 3.2 \\
\hline
\end{tabular}

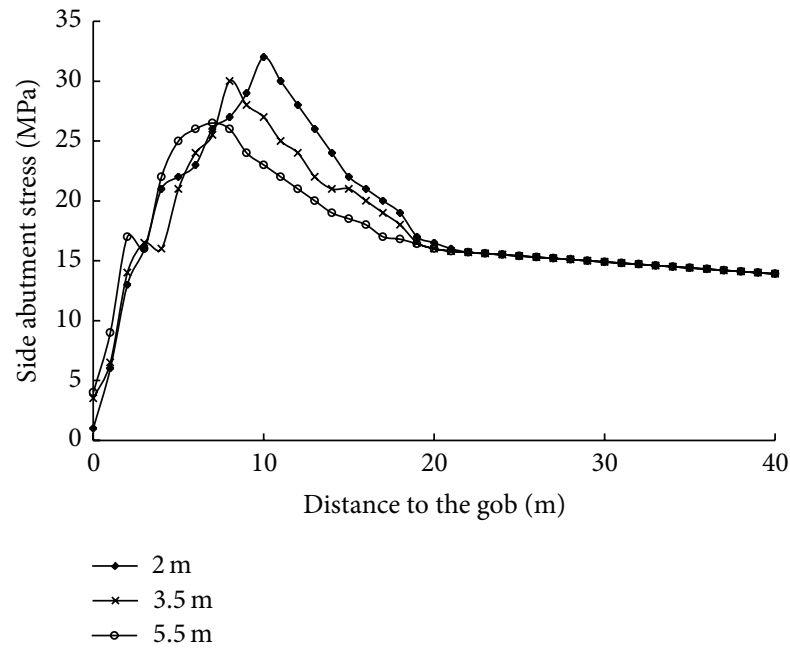

FIGURE 9: Distribution of the side abutment stress for the immediate roof with different thickness.

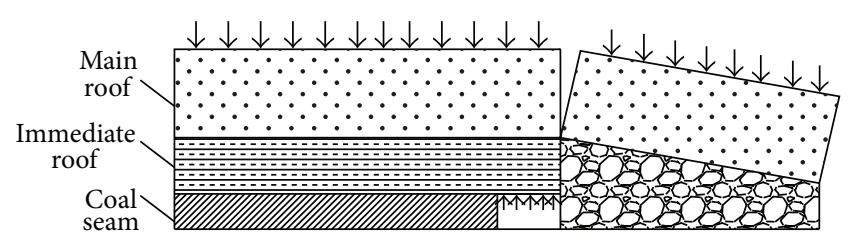

(a) Main roof breaking at the gob side

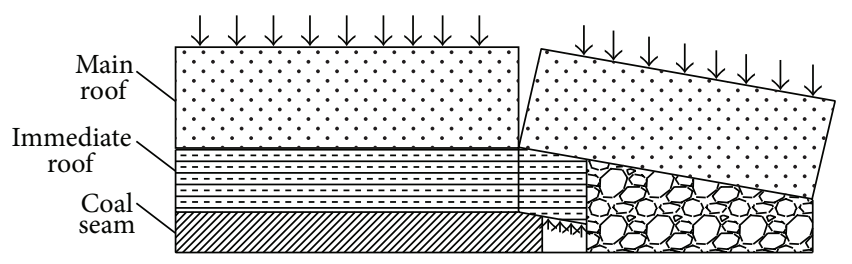

(b) Main roof breaking in the deep area of the coal mass

FIGURE 10: Schematic diagram of the breakage position of the main roof.

1.63, and 1.82, respectively, signifying an increasing trend; compared to the soft immediate roof, the concentration coefficient for the medium hard immediate roof and hard immediate roof increases to $7.9 \%$ and $20.5 \%$, respectively.
4.3.2. The Thickness of the Immediate Roof. According to the geological characteristics of the immediate roof in China, we select the representative thickness of the immediate roof in this study as $2 \mathrm{~m}, 3.5 \mathrm{~m}$, and $5.5 \mathrm{~m}$, respectively. Then we run the numerical simulation to investigate the influences of the thickness of the immediate roof on the distribution characteristics of the side abutment stress. The distribution of the side abutment stress for the immediate roof with different thickness is illustrated in Figure 9.

Figure 9 shows that (1) with the increase of the thickness of the immediate roof, the distance of the position of the peak side abutment stress to the coal wall at the gob increases, while the value of the peak side abutment stress decreases; (2) when the thickness of the immediate roof is $2 \mathrm{~m}, 3.5 \mathrm{~m}$, and $5.5 \mathrm{~m}$, the distance of the peak side abutment stress to the gob is $10.3 \mathrm{~m}, 8.2 \mathrm{~m}$, and $7.2 \mathrm{~m}$, respectively, and the corresponding concentration coefficient for the side abutment stress is 2.1, 2.0, and 1.78, showing a decreasing trend.

4.4. Influences of the Breakage Position of the Main Roof. According to the field monitoring results of the hydraulic support pressure, we get to know that the breakage position of the main roof after the extraction of the coalface is roughly divided into two kinds, the main roof breaking at the gob side and the main roof breaking in the deep area of the coal mass, as shown in Figure 10. Then, we split the grid blocks based on the field monitoring results when we construct the simulation model, which could control the breakage position of the main roof. The distribution of the side abutment stress for the main roof with different breakage position is illustrated in Figure 11.

Figure 11 shows that the breakage position of the main roof exerts minor influences on the peak value of the side abutment stress. When the main roof breaks at the gob side, the distance of the position of the peak side abutment stress to the gob is further compared to the main roof breaks in the deep area of the coal mass, indicating that the width of the stress decreasing zone is larger. Based on the above results, we summarize the factors affecting the distribution of the side abutment stress, as shown in Table 5.

\section{Engineering Application}

5.1. Description of the Study Site. The $3_{2} 14$ coalface is $235 \mathrm{~m}$ on its dip and $2036 \mathrm{~m}$ on its strike. The haulage roadway is 
TABLE 5: Factors affecting the distribution of the side abutment stress.

\begin{tabular}{lcccc}
\hline Influential factor & $\begin{array}{c}\text { Position of the peak side } \\
\text { abutment stress }\end{array}$ & $\begin{array}{c}\text { Peak value of the side } \\
\text { abutment stress }\end{array}$ & $\begin{array}{c}\text { Scope of influence of } \\
\text { side abutment stress }\end{array}$ & $\begin{array}{c}\text { Stress concentration } \\
\text { coefficient }\end{array}$ \\
\hline Coal strength & Inverse ratio & Minor influence & Minor influence & Minor influence \\
\hline Breakage position of the main roof & Minor influence & Minor influence & Minor influence & Minor influence \\
\hline Depth & Direct ratio & Direct ratio & Minor influence & Inverse ratio \\
\hline Immediate roof strength & Inverse ratio & Direct ratio & Minor influence & Direct ratio \\
\hline Immediate roof thickness & Inverse ratio & Inverse ratio & Minor influence & Inverse ratio \\
\hline
\end{tabular}

Note: the position of the peak side abutment stress refers to the distance of the side abutment stress to the gob.

laid out along the gob of the $3_{2} 14$ coalface, as illustrated in Figure 12. The average depth of the haulage roadway is $600 \mathrm{~m}$ and mining activity is carried out on the $3_{2}$ coal seam. The $3_{2}$ coal seam belongs to the semibright vitrain, with an average thickness of $3.3 \mathrm{~m}$. The barrier pillar was previously designed as $30 \mathrm{~m}$ in width. In order to improve the recovery ratio of the coal resources and to mitigate the tension of the mining plan for the next panel, we propose the idea of retaining the narrow coal pillar through gob-side entry driving and put it into an engineering practice.

\subsection{Designing of the Barrier Pillar between Panels}

\subsubsection{Layout of the Reasonable Position of the Barrier Pillar.} In general, the retaining width of the barrier pillar is related to the seam thickness, seam depth, and its roof and floor properties. For the present, most of the countries engaged in coal mining retain the barrier pillar with a width of $25 \sim 35 \mathrm{~m}$ [23]. The theoretical foundation lies in the fact that when laying out the roadway for the next panel the roadway is out of the influence scope of the abutment stress induced by the former panel, which could not only control the safety and stability of the roadway but also effectively prevent the occurrences of gob water and gas hazards.

However, in China, numerous practices demonstrate that it is feasible for driving the roadway by retaining the narrow coal pillar with a width of $3 \sim 5 \mathrm{~m}$ along the gob. Figure 4 shows that Zone I is the side abutment stress rising zone. Numerical studies prove that the width of this zone is related to the coal strength, coal seam depth, and immediate roof strength. Zone III is the side abutment stress decreasing zone, which is beneficial to the layout of the mining roadway. After adopting reasonable support pattern, roadway laid out in this zone can be effectively controlled during its service life.

5.2.2. Designing of the Width of the Barrier Pillar. The strain of the coal mass on the strike of the panel can be ignored due to the fact that the length of the panel on its strike is far larger than the width of the mining-induced fracture zone and plastic zone within the coal mass. Thus the stress state of the microunits within the facture zone and plastic zone can be reduced to a plane stress problem. Figure 13 illustrates the mechanical model for the stress analysis.

Under the action of the side abutment stress, the coal mass has the tendency of being extruded towards the roadway with respect to the roof and floor. Therefore, the shear

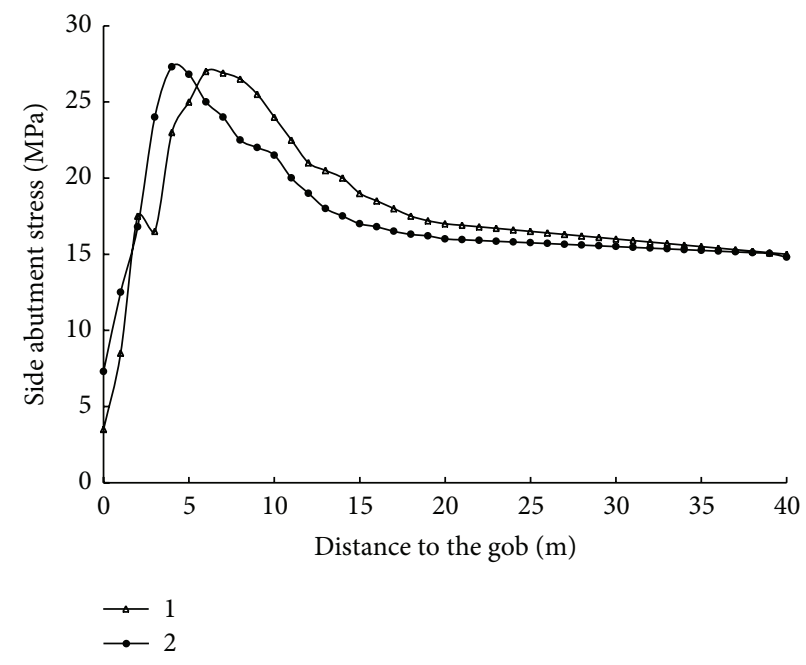

FIGURE 11: Distribution of the side abutment stress for the main roof with different breakage position. 1-main roof breaking in the deep area of the coal mass; 2 -main roof breaking at the gob side.

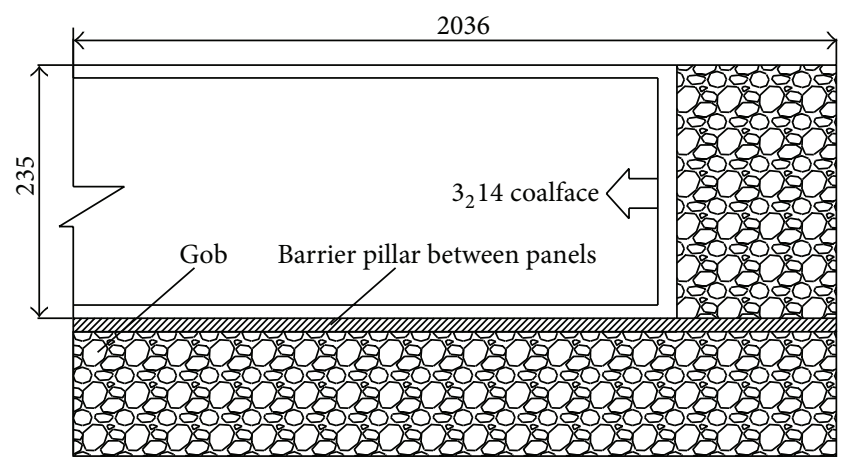

FIGURE 12: Layout of the $3{ }_{2} 14$ coalface and relevant roadways.

between the roof and floor interface could result in the sliding failure of the coal mass. The relation between the normal stress and the shear stress can be expressed as follows:

$$
\tau_{y x}=-\left(\sigma_{y} \tan \varphi_{0}+C_{0}\right)
$$

where $\sigma_{y}$ and $\tau_{y x}$ are the normal stress and shear stress on the roof and floor interface, respectively, and $C_{0}$ and $\varphi_{0}$ are the cohesion and internal friction angle of the rocks on the roof and floor interface, respectively. 


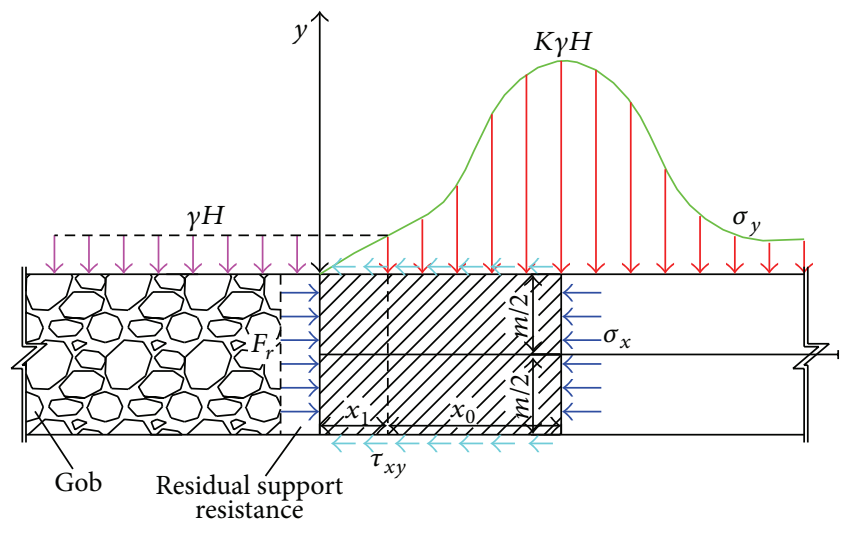

Figure 13: Mechanical model for the analysis of the stress around the gob.

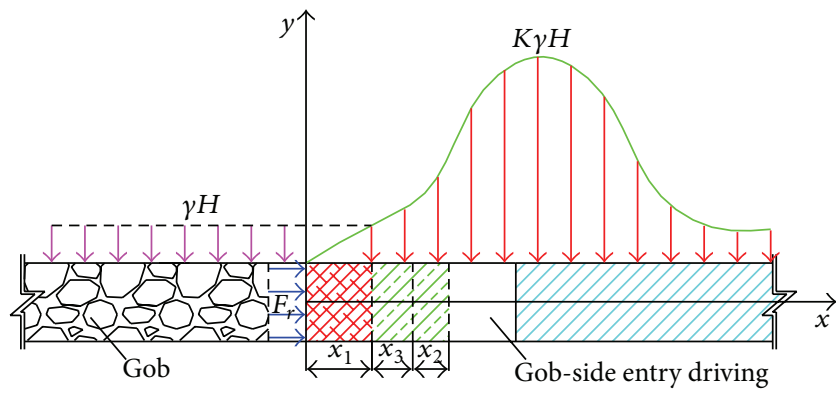

Figure 14: Diagram for the calculation of the reasonable width of the narrow coal pillar.

Without considering the body force, we establish the mechanical calculation model (Figure 13) and the coordinate system. The stress for the microunits at the roof and floor interface follows the following stress equilibrium differential equation:

$$
\begin{gathered}
\frac{\partial \sigma_{x}}{\partial x}+\frac{\partial \tau_{x y}}{\partial y}=0, \\
\frac{\partial \tau_{y x}}{\partial x}+\frac{\partial \sigma_{y}}{\partial y}=0, \\
\tau_{y x}=-\left(\sigma_{y} \tan \varphi_{0}+C_{0}\right) .
\end{gathered}
$$

As shown in Figure 13, $x_{1}$ represents the width of the fracture zone. The boundary condition for the stress in the fracture zone is as follows:

$$
\begin{gathered}
\left.\sigma_{y}\right|_{x=0}=0, \\
\left.\sigma_{x}\right|_{x=0}=P_{x}, \\
\left.\sigma_{y}\right|_{x=x_{1}}=\gamma H, \\
\left.\sigma_{x}\right|_{x=x_{1}}=\lambda \gamma H,
\end{gathered}
$$

where $P_{x}$ is the residual support resistance of the rib rock bolt adopted in the roadway of the former panel and $\lambda$ is the coefficient of horizontal pressure. $\lambda$ is calculated through the equation $\lambda=\mu /(1-\mu)$, where $\mu$ is Poisson's ratio.

Choosing all the rock mass within the fracture zone as the research object and given $\sum F_{x}=0$, we can obtain

$$
\left.m \lambda \sigma_{y}\right|_{x=x_{1}}+2 \int_{0}^{x_{1}} \tau_{y x} d x-m P_{x}=0 .
$$

Based on the theory of the elastic mechanics [24] and considering (2), (3), and (4), we can calculate the width of the facture zone:

$$
x_{1}=\frac{m \lambda}{2 \tan \varphi_{0}} \ln \left(\frac{\gamma H+C_{0} / \tan \varphi_{0}}{C_{0} / \tan \varphi_{0}+P_{x} / \lambda}\right)
$$

where $m$ is the thickness of the coal seam; $k$ is the concentration factor of the side abutment stress; $\gamma$ is the average density of the overlying strata; $H$ is the depth of the coal seam.

In a similar way, we can also obtain the calculation equation for $x_{0}$, the width of the plastic zone

$$
x_{0}=\frac{m \lambda}{2 \tan \varphi_{0}} \ln \left(\frac{k \gamma H+C_{0} / \tan \varphi_{0}}{C_{0} / \tan \varphi_{0}+\lambda \gamma H / \lambda}\right) .
$$

There is an optimal width of the narrow coal pillar in gob-side entry driving. Firstly, we should lay out the roadway in the stress decreasing zone in order to mitigate the convergence of the surrounding rocks, to control the stability of the surrounding rocks and to improve the recovery ratio of the coal resource. This will require us to design the width of the narrow coal pillar as small as possible. However, if the width of the narrow coal pillar is too small, excavatinginduced fissures will connect and coalesce with the original fissures, resulting in the lack of anchoring foundation for the rock bolt. Therefore, the effectiveness of the bolt support system will diminish and the narrow coal pillar is prone to lose stability. Moreover, coal mass with large fracture zone becomes ineffective in preventing the air leaking problem and in avoiding the leakage of the hazardous air from the gob of the former panel, posing a great threat to the safe extraction of the current panel. Thus the reasonable width of the coal pillar, $W$, should be calculated through the calculation diagram as shown in Figure 14.

Figure 14 shows that the width of the narrow coal pillar is comprised of three parts, as illustrated in

$$
W=x_{1}+x_{2}+x_{3}
$$

where $x_{1}$, the width of the fracture zone caused by the side abutment stress during the advance of the former panel, can be calculated by (5); $x_{2}$ is the effective length of the rib bolt within the narrow coal pillar; $x_{3}$, the safety width in considering the anchoring of the rock bolt to the stable coal, can be calculated by $(0.2 \sim 0.4) \times\left(x_{1}+x_{2}\right) .0 .2 \sim 0.4$ is the safety factor.

5.3. Roadway Support Pattern. Through above analysis, we advance the haulage roadway along the gob, retaining the narrow coal pillar with a width of $5.0 \mathrm{~m}$. A corresponding support pattern, consisting of rock bolt, anchor cable, steel 


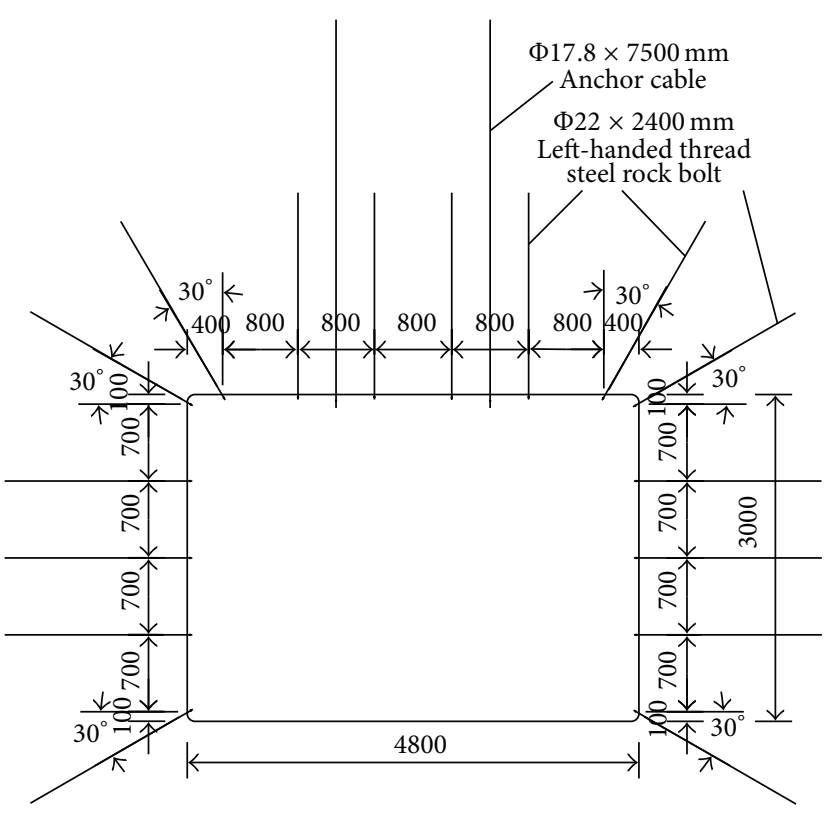

(a) Front view

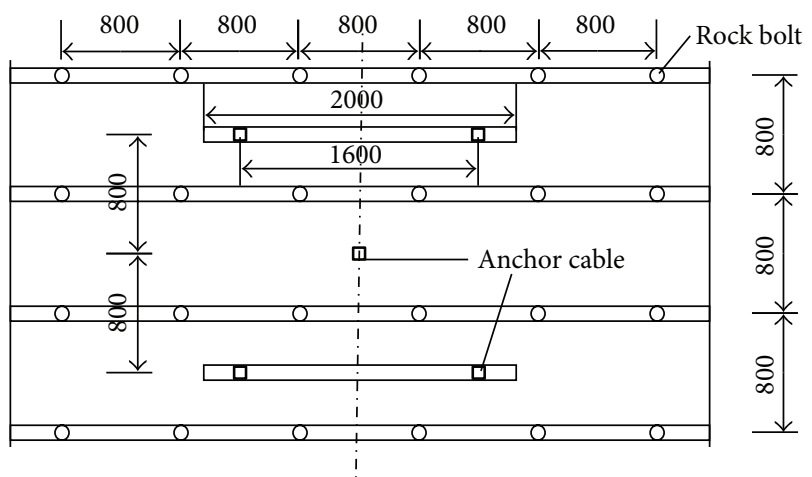

(b) Top view

FIGURE 15: Schematic diagram of roadway support pattern.

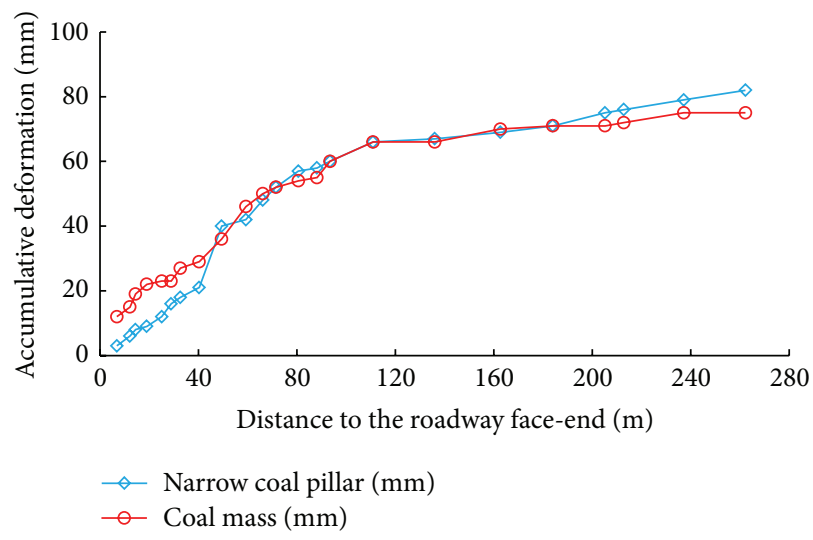

(a) During the advance of the roadway

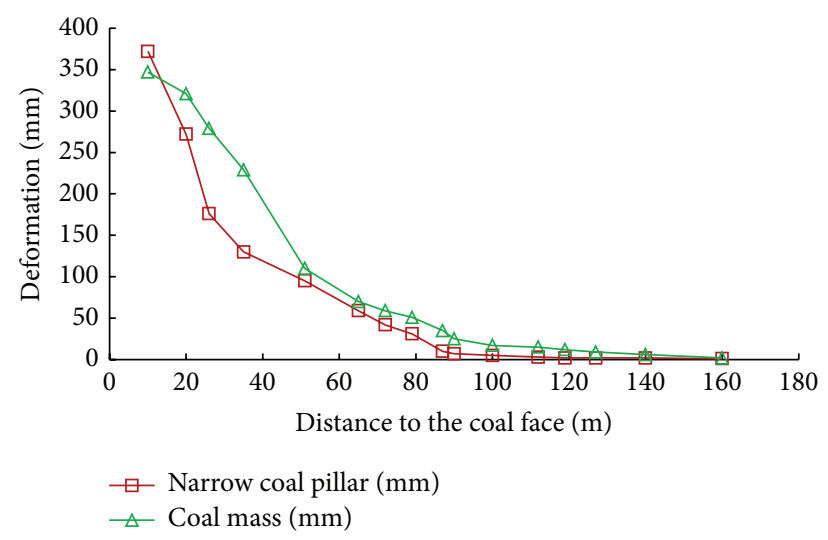

(b) During the extraction of the current panel

FIGURE 16: Monitoring results of the roadway deformation of the surrounding rocks.

strap and rhombic metal mesh, and so forth, was proposed to reinforce the roadway, as illustrated in Figure 15. The detailed support parameters are as follows.

(1) The rock bolt and anchor cable use 2 and 4 resin cartridges of the Z2350 type.

(2) The roof bolts are connected to a steel beam, which has six holes and is $4.8 \mathrm{~m}$ long. The rib bolts are connected with two steel straps, which have three holes and are $1.8 \mathrm{~m}$ long.

(3) The screen mesh for the roof is steel mesh with rhombic holes, while, for the two ribs, plastic mesh is adopted. Both the steel mesh and plastic mesh are $1000 \times 5000 \mathrm{~mm}$ mesh. In the upper corner of the roadway, steel wire is used to bind the steel mesh with the plastic mesh. The overlapping width of the two meshes is larger than $100 \mathrm{~mm}$, while the binding interval is less than $150 \mathrm{~mm}$.

(4) The pretightening torque of the roof and rib bolts is higher than $200 \mathrm{~N} \cdot \mathrm{m}$. The pretension of the anchor cable is higher than $160 \mathrm{kN}$.

\subsection{Support Effect and Economic Benefit}

5.4.1. Roadway Support Effect. Field monitoring of the roadway deformation was carried out to validate the rationality of the proposed pillar width and effectiveness of the support pattern. The results are shown in Figure 16.

Figure 16 shows that (1) the deformation volume of the narrow coal pillar and coal mass is $82 \mathrm{~mm}$ and $75 \mathrm{~mm}$, 
respectively, during the advance of the haulage roadway and is $372 \mathrm{~mm}$ and $347 \mathrm{~mm}$, respectively, during the extraction of the current panel; during these two stages, the roadway can maintain a sufficient profile for the transportation and ventilation requirements; (2) during the advance of the haulage roadway and the extraction of the current panel, both the narrow coal pillar and coal mass demonstrate the same deformation characteristics and both deformations reach stability when the driving face is $90 \mathrm{~m}$ away, while during the extraction of the current panel, the narrow coal pillar and coal mass are subjected to the influences of the front abutment stress when the coalface is $80 \mathrm{~m}$ away.

5.4.2. Yielded Economic Benefit. It is the first time for Qianyingzi coal mine to adopt the gob-side entry driving technology. The barrier pillar was previously designed as $30 \mathrm{~m}$ in width. Through comprehensive researches, we determine the width of the narrow coal pillar as $5.0 \mathrm{~m}$. The $3_{2} 14$ coalface is $2036 \mathrm{~m}$ long on the strike and $235 \mathrm{~m}$ long on the dip. The density of the coal seam is $1.4 \mathrm{t} / \mathrm{m}^{3}$ and its thickness is $3.3 \mathrm{~m}$. After adopting the gob-side entry driving technology, the recovery ratio of the coal is up to $218696.9 \mathrm{t}(25 \times 2036 \times$ $3.3 \times 1.4 \times 0.93=218696.9 t)$. In 2013 , the average price of the coal of Qianyingzi mine is 500 Yuan/t, about 83.3\$. Therefore, this technology can yield 109348450 Yuan $(500 \times 218696.9=$ 109348450), about 18224741.7\$.

\section{Main Conclusions}

(1) In this paper, the borehole stress-meter is used to monitor the distribution characteristics of the side abutment stress during the extraction of the longwall panel in Qianyingzi mine, China. The monitoring results demonstrate that the side abutment stress can be divided into three zones: Zone I, side abutment stress rising zone; Zone II, side abutment stress stabilizing zone; and Zone III, side abutment stress decreasing zone.

(2) In line with the geological setting in Qianyingzi mine, we carried out numerical investigations into the factors that influence the distribution of the side abutment stress. The research results show that the position and value of the peak side abutment stress are closely related to the coal mass strength, immediate roof strength, and immediate roof thickness.

(3) Based on the field monitoring and numerical research results, we put forward the idea of laying out the mining roadway using gob-side entry driving technology. We determined the reasonable position of the mining roadway and the optimal width of the barrier pillar between panels. The engineering application demonstrates that the retention of the barrier pillar with a width of $5 \mathrm{~m}$ along the gob as the haulage roadway for the next panel is feasible, which delivers favorable technological and economic benefits.

\section{Conflict of Interests}

The authors declare that there is no conflict of interests regarding the publication of this paper.

\section{Acknowledgments}

Financial support for this work, provided by the National Natural Science Foundation of China (Grant nos. 51304208 and 51474208) and the Priority Academic Program Development of Jiangsu Higher Education Institutions, is gratefully acknowledged.

\section{References}

[1] S. S. Peng and H. S. Chiange, Longwall Mining, John Wiley \& Sons, New York, NY, USA, 1984.

[2] J. C. Chang, "Distribution laws of abutment pressure around fully mechanized top-coal caving face by in-situ measurement," Journal of Coal Science and Engineering, vol. 17, no. 1, pp. 1-5, 2011.

[3] F. Gao, D. Stead, and J. Coggan, "Evaluation of coal longwall caving characteristics using an innovative UDEC Trigon approach," Computers and Geotechnics, vol. 55, pp. 448-460, 2014.

[4] M. Shabanimashcool and C. C. Li, "A numerical study of stress changes in barrier pillars and a border area in a longwall coal mine," International Journal of Coal Geology, vol. 106, pp. 39-47, 2013.

[5] Z.-H. Ouyang, C.-H. Li, W.-C. Xu, and H.-J. Li, "Measurements of in situ stress and mining-induced stress in Beiminghe Iron Mine of China," Journal of Central South University of Technology, vol. 16, no. 1, pp. 85-90, 2009.

[6] M. Gao, W. Jin, Z. Dai, and J. Xie, "Relevance between abutment pressure and fractal dimension of crack network induced by mining," International Journal of Mining Science and Technology, vol. 23, no. 6, pp. 925-930, 2013.

[7] L.-G. Wang, Y. Song, X.-H. He, and J. Zhang, "Side abutment pressure distribution by field measurement," Journal of China University of Mining and Technology, vol. 18, no. 4, pp. 527-530, 2008.

[8] C. Zhang, Z. Y. Ti, and Z. X. Li, “Theoretical and regressive analysis of the position of peak stress on fully mechanized caving mining," China Safety Science Journal, vol. 21, no. 9, pp. 88-93, 2011.

[9] W. Xu, E. Wang, R. Shen, D. Z. Song, and J. M. Zhang, "Distribution pattern of front abutment pressure of fully-mechanized working face of soft coal isolated island," International Journal of Mining Science and Technology, vol. 22, no. 2, pp. 279-284, 2012.

[10] Z. C. Qin and T. X. Wang, "Abutment stress distribution and its transfer law in floor of deep isolated fully-mechanized mining face using sublevel caving," Chinese Journal of Rock Mechanics and Engineering, vol. 23, no. 7, pp. 1127-1131, 2004.

[11] Z. Hualei, W. Lianguo, and S. Jian, "Distribution of lateral floor abutment pressure in a stope," Mining Science and Technology, vol. 21, no. 2, pp. 217-221, 2011.

[12] B. N. Whittaker and E. L. Potts, "Appraisal of strata control practice: discussion on by BN Whittaker, and authors reply," International Journal of Rock Mechanics and Mining Sciences of Geomechanics Abstracts, vol. 11, no. 11, p. A225, 1974. 
[13] Y.-X. Xia, H. Lan, D.-B. Mao, and J.-F. Pan, "Study of the lead abutment pressure distribution base on microseismic monitoring," Journal of China University of Mining and Technology, vol. 40, no. 6, pp. 868-873, 2011.

[14] N. Hosseini, K. Oraee, K. Shahriar, and K. Goshtasbi, "Studying the stress redistribution around the longwall mining panel using passive seismic velocity tomography and geostatistical estimation," Arabian Journal of Geosciences, vol. 6, no. 5, pp. 1407-1416, 2013.

[15] N. Zhang, N. C. Zhang, C. L. Han, D. Y. Qian, and F. Xue, "Borehole stress monitoring analysis on advanced abutment pressure induced by Longwall Mining," Arabian Journal of Geosciences, vol. 7, no. 2, pp. 457-463, 2014.

[16] B. Shen, "Coal mine roadway stability in soft rock: a case study," Rock Mechanics and Rock Engineering, vol. 47, no. 6, pp. 22252238, 2014.

[17] F. Gao, D. Stead, and H. Kang, "Numerical simulation of squeezing failure in a coal mine roadway due to mininginduced stresses," Rock Mechanics and Rock Engineering, vol. 44, no. 9, pp. 1-11, 2014.

[18] J. Coggan, F. Q. Gao, D. Stead, and D. Elmo, "Numerical modelling of the effects of weak immediate roof lithology on coal mine roadway stability," International Journal of Coal Geology, vol. 90-91, pp. 100-109, 2012.

[19] W.-J. Wang, L.-Q. Luo, W.-J. Yu, H. Wu, and Y.-S. Qu, "Study of dynamic pressure roadway supporting scheme under condition of thick composite roof," Journal of Coal Science and Engineering, vol. 19, no. 2, pp. 119-125, 2013.

[20] M. G. Qian and P. W. Shi, Mining Pressure and Strata Control, China University of Mining and Technology Press, Xuzhou, China, 2003.

[21] P. Liu and Y. J. Zhao, "Technology status and development trend of shearer for difficult mining coal seam," Colliery Mechanical and Electrical Technology, vol. 1, pp. 48-50, 2011.

[22] L. J. Zhu, H. X. Li, and J. J. Chen, "Probing into problems and countermeasures about mining in deep-lying," Coal Technology, vol. 26, no. 6, pp. 146-147, 2007.

[23] M. Shabanimashcool and C. C. Li, "A numerical study of stress changes in barrier pillars and a border area in a longwall coal mine," International Journal of Coal Geology, vol. 106, pp. 39-47, 2013.

[24] Z. L. Xu, Elastic Mechanics, Higher Education Press, Beijing, China, 2006. 

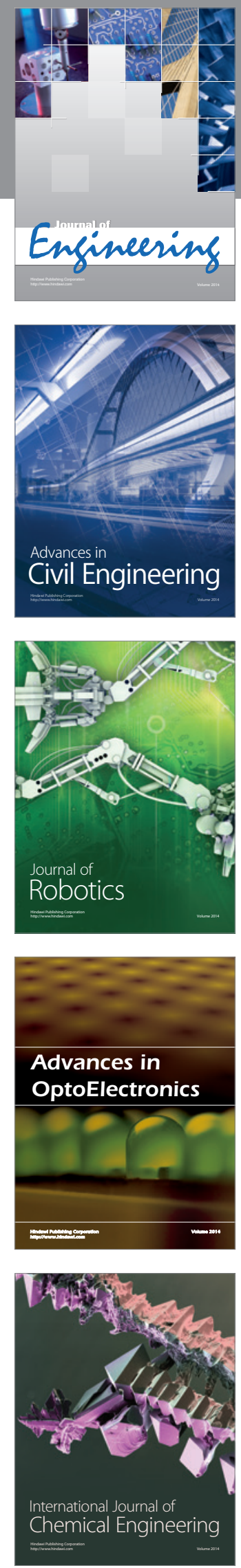

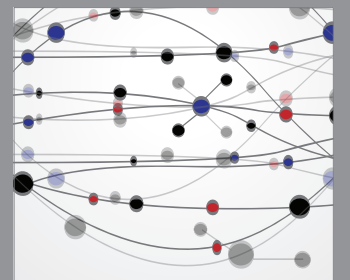

The Scientific World Journal
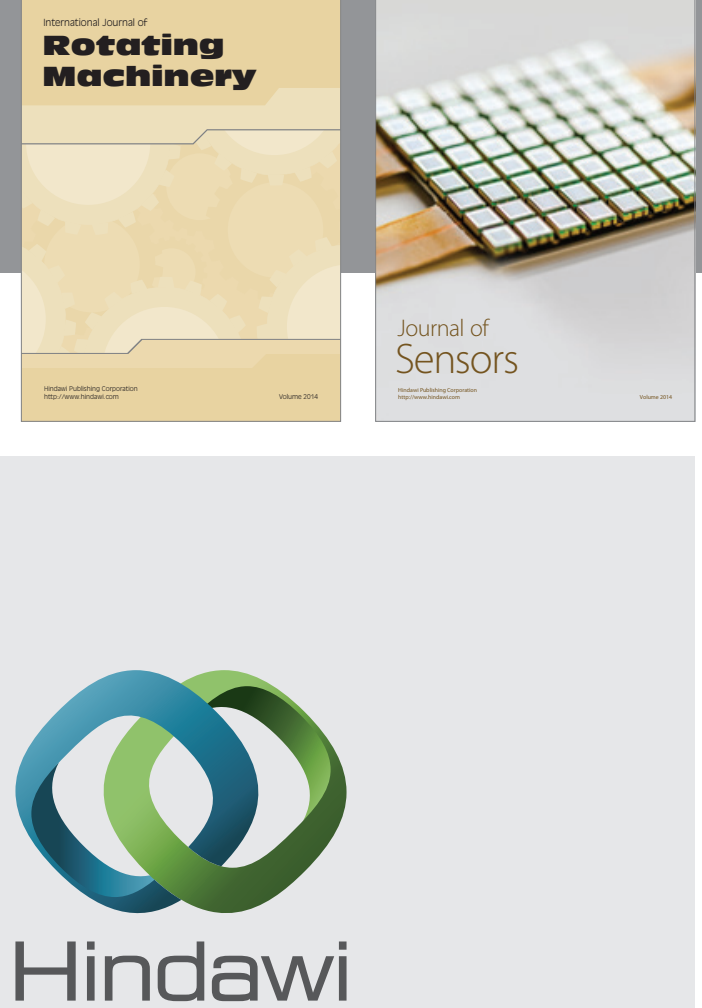

Submit your manuscripts at http://www.hindawi.com
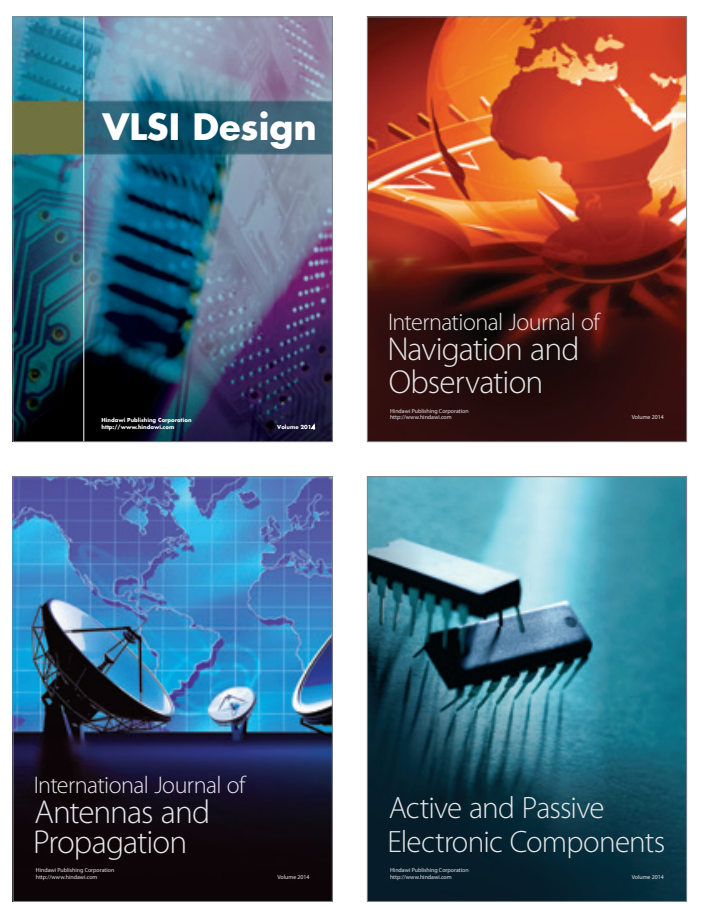
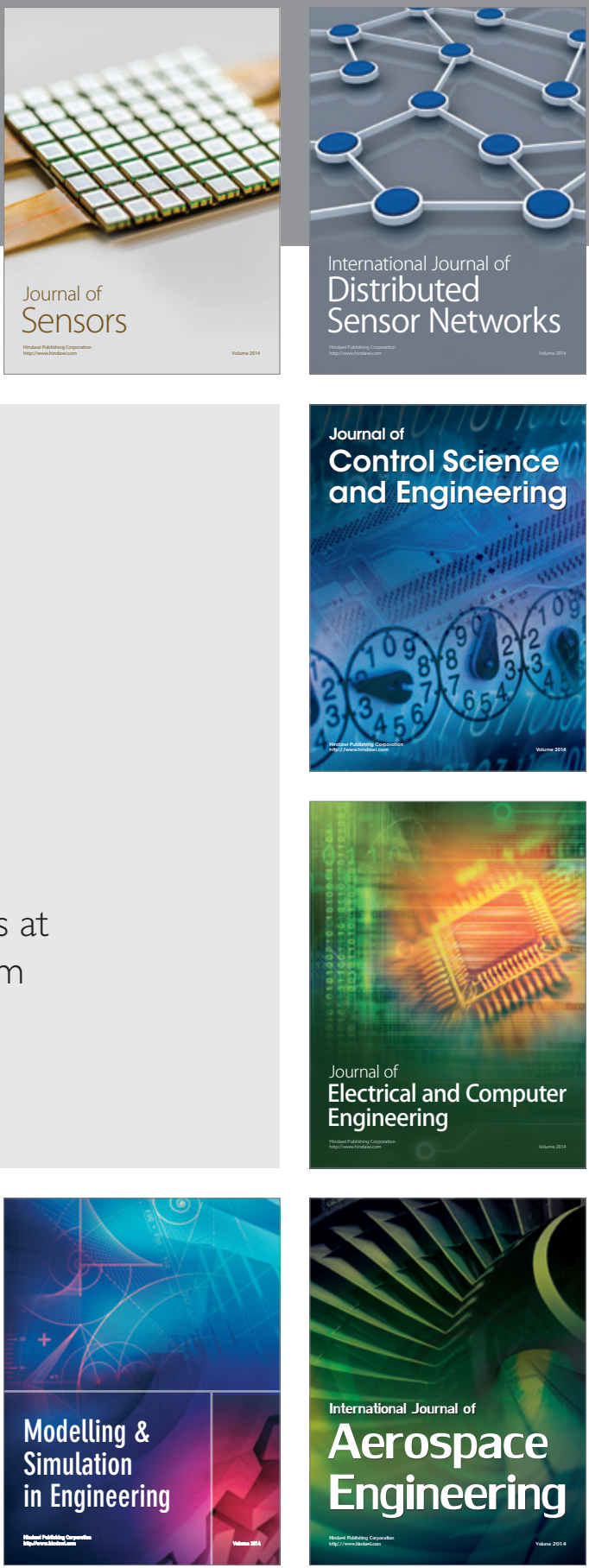

Journal of

Control Science

and Engineering
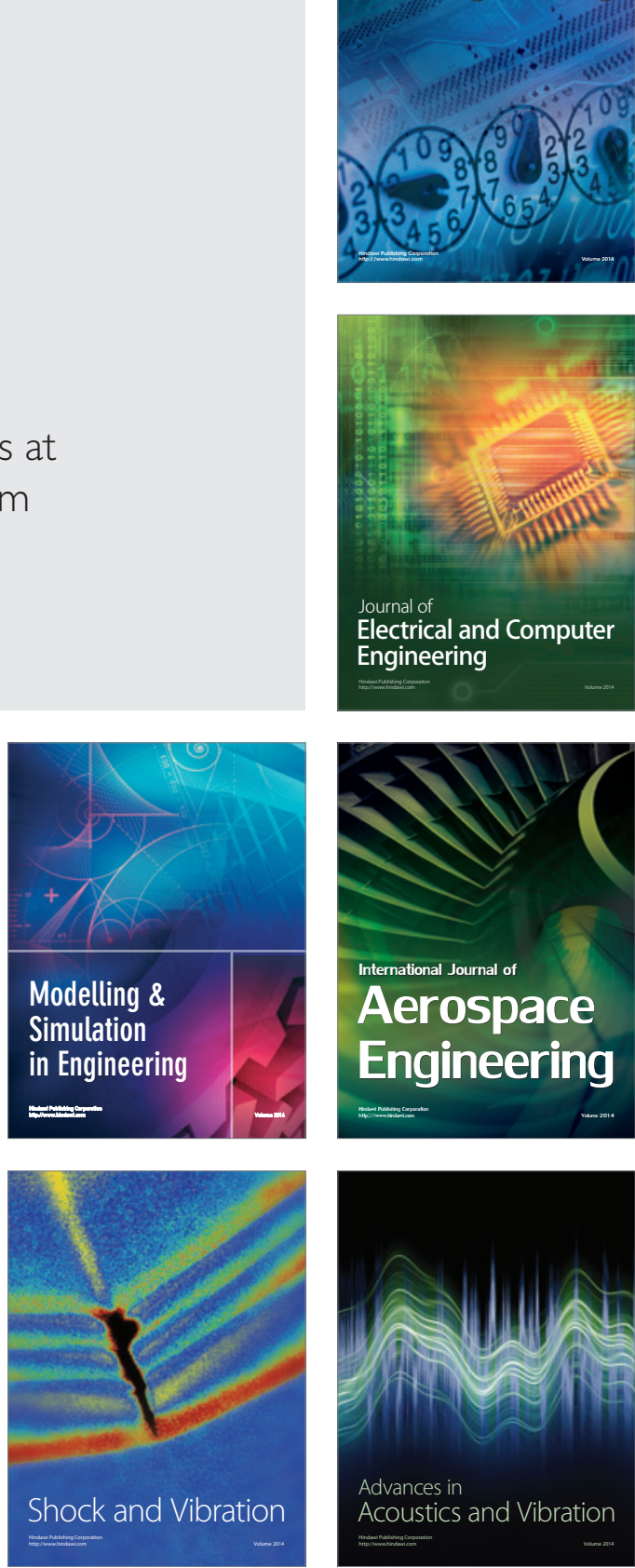